\title{
ASPECTOS CONSTITUCIONALES DEL DEFENSOR DEL PUEBLO
}

\author{
POR \\ ALBERTO PEREZ CALVO \\ Profesor adjunto de Derecho Político \\ Facultad de Derecho de San Sebastián
}

INTRODUCCION *

a) Aunque podrían encontrarse similitudes entre el Defensor del Pueblo y otras figuras que nos brinda la historia como, por ejemplo en nuestro país, el Justicia Mayor de Aragón, la institución creada por la Constitución española de 1978 aparece inspirada directamente en la figura del Ombudsman por lo que parece necesario trazar brevemente los rasgos históricos de esta última institución de origen sueco.

En el siglo xvirI, Suecia ofrecía unas líneas de organización política parecidas a las de las demás monarquías europeas. Y así, la Administración y la Justicia dependen del rey y se ejercen en su nombre. En 1719, el monarca sueco, sobre la base de instituciones anteriores propias del país, crea el Justitiekansler con la misión de tenerle informado de las actividades de jueces y funcionarios.

Hacia 1720 comienza en Suecia la llamada «Era de la libertad» que se caracteriza por un desplazamiento del poder político del monarca al Parlamento. En estas circunstancias, el Justitiekansler pasa a ser un mandatario del Parlamento y supervisa en su nombre a la Justicia y a la Administración. Esta experiencia, que finaliza con el restablecimiento del poder real, dejará, sin embargo, una huella que llegará hasta la Constitución sueca de 1809.

La Constitución de 1809 se inspira en el principio de: «El poder ejecutivo para el Rey, el control para el Riksdag». Al mismo tiempo, mantiene separados al Gobierno y a la Administración de manera que, siendo el rey jefe de ambas, ésta última continúa dependiendo del monarca, situación que a nivel jurídico se mantiene hasta nuestros días.

Por otro lado la Constitución mantuvo las sesiones del Parlamento en un principio quinquenales y después cada tres años. En estas circunstancias, el

\footnotetext{
* Agradezco a mi amigo Jesús Leguina, catedrático de Detecho administrativo, la ayuda prestada para matizar algunos puntos de este trabajo.
} 
Parlamento exigió la creación del Justitieombudsman que, con funciones simétricas a las del Justitiekansler, que seguía y sigue dependiendo del rey, sería nombrado por el Riksdag y publicaría anualmente un informe de sus actividades durante el intervalo de las sesiones parlamentarias. Al mismo tiempo, al Justitieombudsman, mandatario permanente del Riksdag, se le encomienda la recepción de demandas y quejas de los ciudadanos en virtud del derecho de petición que poco antes se había extendido en Europa. Pero como el Justitieombudsman nace precisamente para cubrir la ausencia del Parlamento y no puede acudir a éste para denunciar las actividades ilegales de la Administración, se le concede la posibilidad de acusar a los funcionarios ante los Tribunales.

Quizá pueda completarse esta esquemática exposición acerca del nacimiento del Ombudsman, si aludimos a la lógica desconfianza del Partido constitucional hacia los funcionarios del antiguo régimen y al hecho de que el cambio de estructuras constitucionales no significó inmediatamente una transformación de las estructuras cuasifeudales de Suecia, de manera que los individuos permanecían a merced de los caciques locales y necesitaban una protección legal contra sus abusos.

A lo largo del tiempo, este mandatario permanente del Parlamento va a sufrir una doble evolución. El Ombudsman, que en un principio nace como una institución que se encarga de la vigilancia de la Administración y de la Justicia, lo que equivale a decir que se ocupa de la vigilancia del rey, va perdiendo parte de este carácter hasta convertirse en una institución de supervisión de las actividades de la Administración y de la Justicia. Otra línea de evolución que merece destacarse consiste en que paulatinamente tiene lugar una disminución de las actividades acusatorias del Ombudsman en beneficio de sus actuaciones no contenciosas.

Esta doble evolución, debida la primera a la transformación parlamentaria del sistema de gobierno, y la segunda al desarrollo de otro tipo de medidas para corregir las ilegalidades de los funcionarios, la tuvieron en cuenta los daneses cuando, en base a la reforma constitucional de 1953, introdujeron en el año siguiente la institución del Ombudsman en su país, adaptándolo al sistema de gobierno parlamentario típico $\mathrm{y}$ atribuyéndole fundamentalmente competencias no contenciosas.

Previamente la institución había sido adoptada por Finlandia y Noruega, pero, por las razones anteriores, el Ombudsman comienza a extenderse por todo el mundo a partir de la institución danesa ${ }^{1}$.

b) De la lectura de los preceptos constitucionales referidos al $\mathrm{DP}^{2}$ se desprende la relación de esta institución con las Cortes Generales, con el Tribunal Constitucional e indirectamente con el Gobierno a través de su contacto con la Administración. Es decir, la posición que ocupa el DP no es ajena al equilibrio existente entre los poderes del Estado.

${ }^{1}$ Cfr. A. Legrand, L'Ombudsman scandinave. Etudes comparées sur le contrôle de l'Administration, LGDJ, París, 1970, págs. 27-28.

2 Artículos 54, 70 y 162. 
Los constituyentes españoles han encontrado frente a sí a un Estado muy lejano del clásico liberal, a un Estado que interviene sistemáticamente y en gran escala en el terreno económico y social, al que tratan de constitucionalizar y someter a Derecho.

La naturaleza interventora de este Estado, que la Constitución no crea sino que únicamente trata de encauzar por derroteros democráticos, tiene consecuencias directas sobre el equilibrio de los poderes clásicos. Existe abundante literatura que analiza cómo este tipo de Estado intervencionista ha generado en las sociedades occidentales un predominio del ejecutivo sobre el legislativo que se manifiesta, aparte otros supuestos, en diversos momentos del proceso legislativo. Se trata de los conocidos fenómenos de la legislación delegada, de los decretos de urgencia, etc. Se trata igualmente del hecho de que el Parlamento básicamente genera normas no directamente aplicables sino que las leyes que emanan de él se concretan posteriormente en los correspondientes desarrollos reglamentarios y su aplicación corre a cargo de la compleja burocracia administrativa subordinada, en principio, al ejecutivo. Es decir, en el proceso legislativo, lo que equivale a decir el proceso básico de decisión del Estado, el Parlamento queda alejado de aspectos tan fundamentales como, por regla general, de la iniciativa y, desde luego, de las múltiples decisiones necesarias para la aplicación de la ley. Para tener una influencia en estos aspectos, al Parlamento, institución que hoy por hoy expresa con mayor fidelidad que ninguna otra la representación de los distintos sectores y capas sociales, así como las diferentes corrientes ideológicas, no le queda más recurso que el de intentar obstaculizar y controlar determinadas actividades de la Administración, cuando se observe que éstas se separan de los objetivos hacia los que tiende la ley.

Esta situación del Parlamento, no tan lejana de la del Riksdag sueco de 1809 , puede constituir el basamento para un desarrollo del control parlamentario de la Administración, sin perjuicio del mantenimiento del, entre nosotros tradicional, autocontrol administrativo y control jurisdiccional.

\section{LA FORMACION DE LA INSTITUCION}

El artículo 54 atribuye a las Cortes Generales la regulación de la institución del DP mediante ley orgánica y la designación de la persona que vaya a desempeñar la función.

Uno de los problemas clave que se plantean en el Derecho comparado en relación con las instituciones en las que se inspira el DP es el mayor o menor grado de dependencia con respecto al Parlamento. En todos los casos, el Ombudsman está creado por la Constitución, y su regulación detallada y nombramiento corren a cargo del Parlamento. Pero mientras, por ejemplo, en Suecia y Dinamarca el nombramiento a cargo del Parlamento significa únicamente la garantía de independencia del Ombudsman con relación al rey y a la Administración, en Noruega y la República Federal de Alemania el Ombudsman depende, a veces estrechamente, del Parlamento que lo nombra.

A la luz de estos dos polos que nos brinda el Derecho comparado, podemos 
examinar la construcción que parece desprenderse de la Constitución española. En primer lugar, hay algo que no por evidente debe dejar de reseñarse: es la propia Constitución la que crea la institución del DP. La misión que la Constitución encarga a las Cortes en este aspecto es la de regular una institución creada por ella.

Por otro lado, la Constitución al crear la institución del DP le atribuye una función - defensa de los derechos comprendidos en el Título I- y unos medios para el desarrollo de la función — supervisión de la actividad de la Administración y recursos ante el Tribunal Constitucional-, que las Cortes deben respetar a la hora de regular la institución.

La función de defensa de los derechos y libertades parece caracterizar decididamente al DP, incluso desde el punto de vista de la posición sistemática que ocupa la norma que lo crea, al estar situada ésta en el capítulo correspondiente a las garantías de las libertades y derechos fundamentales dentro del mencionado Título I.

Por otra parte, y es otro mandato constitucional a las Cortes, la regulación de la institución deberá hacerse mediante ley orgánica, lo que significa que dicha regulación deberá contar con la anuencia de la mayoría absoluta del Congreso.

En relación con el nombramiento, el problema más discutido en la doctrina es el de la posible politización del Ombudsman y, en nuestro caso, del DP. No obstante, creemos que la palabra politización entraña dos significados distintos. Si la politización significa que el DP caerá en la órbita de un partido o de una opción política concreta, el riesgo cobra toda su dimensión y el título pomposo de Defensor del Pueblo podría llegar a ser burlesco. Sin embargo, la politización que puede envolver al DP puede tener otro significado. No hay que olvidar que el orden político, económico y social que se pretende construir mediante la Constitución supone una doble beligerancia: desde el punto de vista liberal, contra posibles hábitos autoritarios del pasado y hacia el futuro, en la extensión de los valores de la democracia social. La politización del DP en este último sentido sería, ni más ni menos, la politización que envuelve a la propia Constitución. En este sentido, que el DP asuma esta tarea política puede suponer la aceptación y el respeto hacia la institución por parte de todos y la exclusión de la tentación de utilizar al DP como instrumento de uno $\mathrm{u}$ otro partido.

$\mathrm{Y}$ hasta cierto punto, el problema de la politización es independiente del hecho de que el Ombudsman esté más o menos supeditado al Parlamento, como lo demuestra el ejemplo noruego. En este país, donde el Ombudsman es un instrumento del Parlamento, se cuida con especial esmero mantenerlo alejado de las luchas políticas parlamentarias, y pienso que la explicación reside en que precisamente se pretende que esta institución sea instrumento de todo el Parlamento y que no esté a merced de la mayoría parlamentaria.

Huelga decir que en el Derecho comparado se han resuelto estos problemas estableciendo mayorías cualificadas tanto para la designación como para la eventual revocación del titular. Y la práctica, por ejemplo en Suecia, consiste en buscar la unanimidad a través del acuerdo de los portavoces de los grupos parlamentarios. 
Aunque la Constitución no dice nada al respecto, ofrece sin embargo argumentos para defender que la designación del DP se haga mediante mayorías cualificadas. La función de defensa de los derechos y libertades atribuida al DP, junto con los medios señalados para ello, le colocan en una situación lo suficientemente distante de la órbita parlamentaria como para que su nombramiento no deba ser acaparado por una formación que represente la mayoría simple. Y la única manera de asegurar la distancia señalada con respecto a las Cortes es hacer que la designación dependa de la conjunción de un máximo de voluntades políticas representadas en ellas. Por otra parte, es preciso tener en cuenta el peligro de estancamiento a que se puede llegar en materia de nombramientos, si el techo de votos requeridos fuese demasiado alto o el fraccionamiento político de las Cortes fuese asimismo elevado. Por otro lado, el artículo 70 señala la incompatibilidad existente entre el cargo de DP y el de parlamentario. Lo que, además de constituir otro límite impuesto a las Cortes en relación con sus poderes respecto del DP, parece ir en el sentido de distanciar al DP de las mismas. Esta incompatibilidad es perfectamente lógica en relación con la función y medios atribuidos al DP.

Las consideraciones anteriores, así como la lógica que parece desprenderse de la Constitución que, aun situando al DP en el ámbito de las Cortes, lo mantiene a una determinada distancia de las mismas, nos brindan una serie de criterios desde los que podrían enfocarse algunas líneas maestras en relación con el estatuto del DP.

Así, en cuanto a la duración en el cargo, parece que deberían conjugarse los criterios de eficacia, renovación y relativa independencia respecto de las Cortes. La eficacia, que implica adquisición de experiencia y la permanencia necesaria para conquistar la confianza de los ciudadanos - y esto, tanto desde el punto de vista personal de quien ocupe el cargo como del de la propia institución, desconocida hasta ahora en nuestro país-, exige, como es lógico, una permanencia prolongada en el cargo. El dejar paso a una eventual renovación en cuanto a personas y criterios demanda que la permanencia aludida no sea excesivamente larga ${ }^{3}$. Finalmente, el criterio de independencia relativa respecto de las Cortes, junto con las conclusiones que pueden extraerse de los criterios anteriores, podrían dar la pauta de una duración en el cargo de cinco años, de manera que se aparte del período de elección de cuatro años de las Cortes Generales ${ }^{4}$.

Relacionado con el problema de la duración en el cargo está el de su inamovilidad temporal, necesaria para la independencia en sus actuaciones, incluso frente a las mismas Cortes. Y que debería conjugarse a modo de contrapartida, con la posibilidad de que las mismas Cortes pudieran revocarle, posibilidad esta última tendente a impedir un eventual abuso de las funciones. La resultante de estos dos criterios opuestos podría conseguirse estableciendo para la revocación del titular las mismas condiciones que para su nombramiento.

${ }^{3}$ En Suecia se tiende a períodos cortos para evitar la burocratización; véase Legrand, op. cit., pág. 60 .

${ }_{4}^{4}$ Tal es el criterio seguido en la República Federal Alemana; véase $\mathrm{E}$. Lohse, $E l \ll O m$ budsman» militar en Alemania Occidental, en D. C. Rowat, El «Ombudsman». El defensor del ciudadano, FCE, Méjico, 1973, pág. 172. 
Finalmente, en consonancia con los criterios precedentes, parece necesario que el equipo colaborador sea designado por el DP y que dependa única y exclusivamente de éste, a partir des la cantidad que le asignen las Cortes con cargo al presupuesto de las mismas ${ }^{5}$.

En resumen, desde el punto de vista de la formación de la institución, podemos señalar que la regulación de la misma, así como la designación de su titular, además de otros argumentos que veremos posteriormente, sitúan al DP dentro del ámbito de las Cortes. No obstante, de las normas constitucionales que crean la institución, que preordenan determinados perfiles de la misma y que establecen la incompatibilidad señalada, parece desprenderse una línea lógica tendente a mantener al DP en una relativa independencia orgánica respecto de las Cortes.

\section{LA FUNCION DE DEFENSA DE LOS DERECHOS COMPRENDIDOS EN EL TITULO I DE LA CONSTITUCION}

$\mathrm{El}$ artículo 54, que crea la institución del DP, le asigna a éste la función de defensa de los derechos comprendidos en el Título I, lo que parece dar a entender que todos los problemas que puedan plantearse en torno a la formación, estatuto y organización del DP, así como en relación con sus medios de actuación, deberán resolverse atendiendo a dicha función. Asimismo, el DP tomará los criterios últimos que inspiren sus actuaciones del objeto mismo de su función de defensa, es decir, de los derechos y libertades tal como los ampara la Constitución y de la jurisprudencia del Tribunal Constitucional acerca de ellos. De lo anterior se desprende que su último criterio de actuación radica en la Constitución, y no en la ley, afirmación ésta que puede tener consecuencias importantes en cuanto a la situación institucional del DP.

No obstante, en relación con el problema que acabamos de esbozar, conviene que distingamos dos situaciones nacidas de los distintos medios atribuidos al DP para el desarrollo de su función. Para asegurar la función de defensa de los derechos y libertades, la Constitución atribuye al DP: 1) la potestad de supervisar la actividad de la Administración; 2) la legitimación para interponer los recursos de inconstitucionalidad y de amparo.

Cada uno de estos medios tiene una incidencia distinta en cuanto a la posición institucional del DP en relación con los poderes instituidos. Y hasta cierto punto, podría afirmarse que lo que ha hecho la Constitución es añadir las legitimaciones mencionadas a las competencias que acompañan al modelo de Ombudsman adoptado por los daneses y que se había perfilado históricamente en Suecia, y una de cuyas características, según dijimos, estribaba en una ausencia práctica de competencias contenciosas.

A partir de lo dicho, parece conveniente que analicemos separadamente ambos puntos.

${ }^{5}$ Es el criterio seguido en los países nórdicos; Legrand, op. cit., pág. 264. 


\section{La legitimación del Defensor del Pueblo ante el Tribunal Constitucional}

El artículo 162 legitima al DP para interponer los recursos de inconstitucionalidad y de amparo. Aquí también podemos señalar que la posición institucional del DP será distinta en función de cada uno de los recursos señalados.

Mientras que la legitimación para interponer el recurso de amparo coloca al DP, objetivamente, en la situación de un recurrente contra las sentencias de los tribunales ordinarios ${ }^{6}$, la legitimación para interponer el recurso de inconstitucionalidad, supuesto que presenta mayor interés, desde nuestro punto de vista, plantea, entre otros, uno de los aspectos del problema general de la relación del DP con las Cortes Generales, como vamos a comprobar posteriormente.

Aparecen claras las diferencias que separan a la potestad atribuida al DP para supervisar las actividades de la Administración y la legitimación para interponer el recurso de inconstitucionalidad. En el primer caso, el objeto de la investigación del DP es la actividad de la Administración. En el segundo se trata de las leyes y disposiciones normativas con fuerza de ley.

Además, las consecuencias que pueden derivarse de una u otra actividad difieren esencialmente. La sụpervisión de la actividad de la Administración puede desembocar, entre otras salidas posibles, en un informe a las Cortes Generales, que podrán pronunciarse o no al respecto en función de criterios de oportunidad y que, en caso de emitir un juicio y de adoptar una medida, ésta sería también de carácter político. Así se engrana la supervisión, de carácter fundamentalmente administrativo del DP con el control político de las Cortes. En cambio, la supervisión, si así puede llamarse, de la actividad legislativa puede dar lugar a un recurso ante el Tribunal Constitucional, instancia jurisdiccional, que deberá pronunciarse obligatoriamente sobre el asunto y con arreglo a criterios jurídicos.

Por otro lado, los criterios en que deba apoyarse la actuación del DP son también distintos en ambos casos. A la hora de supervisar las actividades de la Administración, el DP tomará sus criterios, en primer lugar, del Título I de la Constitución y jurisprudencia del Tribunal Constitucional al respecto, y también, en la medida en que así lo dispone el propio Título I, artículo tras artículo, de las leyes que elaboren las Cortes Generales para la regulación de los derechos y libertades. En cambio, a la hora de interponer el recurso de inconstitucionalidad, el DP proyectará su mirada crítica sobre la ley o disposiciones normativas con fuerza de ley, no dependiendo para ello de otros criterios que los que le brinde el Título I, los procedimientos de elaboración de las leyes previstos en la propia Constitución y la jurisprudencia del Tribunal Constitucional.

- O. Alzaga, Comentario sistemático a la Constitución española de 1978, Ediciones del Foro, Madrid, 1979, pág. 937, señala que «en la práctica no parece lógico esperar la intervención del Defensor del Pueblo - salvo que en torno a esta figura se cree un aparato burocrático de grandes proporciones-y sí, por el contrario, la del Ministerio Fiscal». 
El hecho de que se haya atribuido al DP la legitimación para acudir al Tribunal Constitucional no está exento de problemas. A este respecto, el profesor De Vega criticaba rotundamente que con un sistema de jurisdicción constitucional concentrada y de justicia administrativa como se dan en nuestro país se hubiera optado por una configuración del DP como magistratura «de acción judicial y legalista», en lugar de mantenerlo dentro de los límites de una «magistratura de opinión»?

Es cierto que, como señala el profesor Alzaga, saliendo al paso de las críticas esgrimidas por algunos en el sentido de que la legitimación para interponer el recurso de inconstitucionalidad estaría dispuesta de manera que sólo pudieran tener acceso a ella los grandes partidos políticos, el DP puede servir de cauce para recursos de este tipo promovidos por cualquier persona que se sienta injustamente afectada por una ley ${ }^{8}$.

Pero, a pesar de todo, es preciso tener en cuenta el temor expresado por Pedro de Vega a propósito de que el DP podría quedar totalmente desfigurado de manera que no funcionara ni como magistratura de opinión ni como mecanismo legal de defensa del ciudadano, e incluso, sigue apuntando el mismo profesor, «que impidiera el funcionamiento de otras instituciones como la Justicia Constitucional» 9 .

Sin perjuicio de las críticas anteriores, la legitimación atribuida al DP para interponer el recurso de inconstitucionalidad afecta a las relaciones tanto orgánicas como funcionales de esta institución con las Cortes Generales.

En cuanto a la relación orgánica del DP con las Cortes Generales, el problema se centra en la designación o eventual revocación del titular de la institución. Desde el momento en que al DP se le atribuye la legitimación para interponer el recurso de inconstitucionalidad, todas las cautelas destinadas a garantizar la independencia del DP de una simple mayoría parlamentaria adquieren aquí, si cabe, una mayor significación. En efecto, el nombramiento o posible revocación de un DP, que tiene la posibilidad de atacar ante el Tribunal Constitucional las leyes de las mismas Cortes, los decretos del Gobierno y las disposiciones normativas con fuerza de ley de las comunidades autónomas, podría generar duras batallas políticas.

En lo que atañe al aspecto funcional del DP en esta materia, puesto que los únicos criterios a los que debe atender emanan de la propia Constitución o de la jurisprudencia constitucional, parece lógico que la ley orgánica reguladora de la institución deba limitarse en todo caso a dejar constancia de la legitimación del DP para interponer el citado recurso.

Finalmente, cabe plantear otra cuestión que puede ayudar a delimitar la posición que ocupa el DP, en cuanto legitimado para interponer el recurso de inconstitucionalidad, en relación con las Cortes Generales.

La Constitución habla de que el recurso de inconstitucionalidad podrá interponerse contra leyes o disposiciones normativas con fuerza de ley (art. 161-a).

${ }^{7} \mathrm{P}$. de Vega, Los órganos del Estado en el contexto político-institucional del proyecto de Constitución, en La Costituzione Spagnola nel trentennale della Costituzione italiana, Bolonia, 1978, pág. 11.

O. Alzaga, op. cit., pág. 936.

$\rightarrow$ P. de Vega, op. cit., pág. 11. 
Dejando a un lado los tratados internacionales, para los que la Constitución prevé un procedimiento especial de control constitucional (art. 95), las disposiciones con fuerza de ley a las que se refiere el artículo 161-a son, además de las disposiciones de este rango de las comunidades autónomas, los decretosleyes y los decretos legislativos.

En el caso de los decretos-leyes, el artículo 86-2 establece un control sobre los mismos en favor del Congreso, de manera que, dentro de un determinado plazo, esta Cámara deberá pronunciarse sobre su convalidación o derogación. En relación con los decretos legislativos, la Constitución no pone en manos de las Cortes un control automático, como en el caso anterior, sino que el artículo 82-6 prevé que «las leyes de delegación podrán establecer en cada caso fórmulas... de control».

El problema que cabe plantear gira en torno al momento en que el DP podrá eventualmente interponer el recurso de inconstitucionalidad en relación con los decretos-leyes y decretos legislativos. En principio, la respuesta lógica parece ir en el sentido de que, en relación con los decretos-leyes, el DP no podrá intervenir hasta que el Congreso se pronuncie sobre los mismos. $Y$ en el caso de los decretos legislativos, la respuesta deberá ser la misma, siempre que la ley de delegación haya establecido una determinada fórmula de control por parte de las Cortes.

Las razones que juegan en favor de esta solución estriban, en primer lugar, en que parece lógico pensar que los decretos-leyes sólo alcanzarán su perfección legislativa plena una vez que el Congreso haya usado del poder de control atribuido por la Constitución, lo que equivale a decir que el control atribuido al Congreso, caracterizado por su accesoriedad con respecto al acto controlado, se exige como un elemento necesario para la eficacia plena del decreto-ley. La misma razón cabe aducir en el caso de los decretos legislativos cuando la ley de delegación correspondiente haya establecido las fórmulas de control del artículo 82-6.

Interviene también una segunda razón, que en realidad constituye una explicación de la que acabamos de señalar. Tanto el control automático previsto en relación con los decretos-leyes como el control eventual en relación con los decretos legislativos corresponden a las Cortes en virtud de la potestad legislativa que a esta institución reconoce la propia Constitución en su artículo 66-2, así como también en virtud del poder general de control sobre la acción del Gobierno que le atribuye el mismo artículo.

De esta manera el DP, al utilizar eventualmente su recurso una vez que las Cortes se hayan pronunciado, además de respetar la potestad legislativa que genuinamente corresponde a las Cortes, respetaría también la relación entre controlado y controlante del Gobierno con respecto a las mismas, tal como se desprende de la construcción prevista por la Constitución ${ }^{10}$.

10 En virtud de un razonamiento paralelo al anterior, cabe pensar que el Derecho penal podrá recurrir ante el Tribunal Constitucional contra los tratados internacionales siempre que el mismo Tribunal no se haya pronunciado previamente sobre la cuestión según se contempla en el artículo 95-2. 


\section{La supervisión de la Administración y el sistema de gobierno español}

A) Ambito de competencia. Son varios los problemas que cabría plantear en torno a esta cuestión. Uno de ellos es el que afecta al DP en relación con la organización territorial del Estado sobre la base de comunidades autónomas. Desde este punto de vista, si tenemos en cuenta que los niveles administrativos regionales van a tener una importancia en algunos casos superior a los centrales, el DP puede adquirir un carácter extraño a su función primaria, como es el de constituir, en tanto que institución dependiente de las Cortes, una nueva modalidad de tutela sobre las comunidades autónomas. Esta alteración de su función primaria podría conducir, como lo ha puesto de relieve Pedro de Vega, a un cierto desprestigio de la institución y, en definitiva, a una merma de su funcionalidad ${ }^{11}$.

Es posible que los futuros estatutos de autonomía recojan en su ámbito una figura insipirada en el DP creado por la Constitución. Sin entrar en el análisis de la cuestión, se puede señalar que, en principio, tanto el DP como la instítución regional inspirada en él tendrían la misma potestad de supervisión en lo que se refiere a la Administración dependiente de las comunidades autónomas respectivas.

Esta situación haría surgir nuevos problemas, puesto que si una de las ventajas de la institución del DP, a raíz de las experiencias del Derecho comparado, es la simplificación al máximo de los trámites para que el ciudadano acceda a él, la existencia de dos instituciones similares podría llevar al ciudadano a tener que resolver previamente la cuestión de las respectivas competencias de una y de otra. La única solución a este problema parece residir en una colaboración entre ambas, de manera que los ciudadanos puedan enviar las peticiones o quejas a uno $\mathrm{u}$ otro indistintamente, $\mathrm{y}$ sean los DP quienes se trasladen las que atañen a sus respectivas competencias. La misma solución, en base a la colaboración entre ambas instituciones, será necesaria para la resolución de otros problemas que podrían surgir.

El intento de delimitar la competencia del DP de supervisión de la actividad de la Administración nos lleva, lógicamente, al campo ocupado por los tribunales de justicia en su función de control de la Administración.

En principio, tal como el DP se nos presenta a partir de la Constitución, no parece que existan interferencias entre éste y la justicia administrativa. En efecto, el supervisar la actividad de la Administración y dar cuenta de ello a las Cortes no parece que pueda afectar en nada a la justicia. Con respecto a la Administración y dejando a un lado el recurso de amparo, que al fin y al cabo existe con independencia del DP y que éste no resuelve, las resoluciones del DP no son obligatorias jurídicamente. En estas condiciones, a nivel jurídicoformal, al menos, el problema no se plantea. Y sin embargo quizá sea éste uno de los problemas más arduos con que deberá enfrentarse la futura ley orgánica que regule al DP, puesto que, aunque las decisiones de un tribunal tengan fuerza jurídica vinculante y las del DP no la tengan, no cabe duda de

${ }^{11}$ Véase P. de Vega, op. cit., págs. 11-12 y 18. 
que estas últimas estarán dotadas también de la autoridad suficiente como para imponerse a sus destinatarios.

En definitiva, aunque actuando en distintos planos, la actividad de los tribunales y del DP podrían entrar en colisión. Y de hecho, como se ha dicho a propósito del Médiateur francés, «su instauración - a menos que se tratara de un simple tributo a la moda o de un planteamiento falso o erróneo- está denunciando la existencia de una importante laguna o insatisfacción en el sistema de la justicia administrativa, hasta ahora valorado como un excelente medio de garantía de las libertades públicas en los países de Derecho administrativo» ${ }^{12}$.

Pero si la experiencia francesa del Médiateur pudo haber abierto un camino en la tarea de conciliar el sistema de la justicia administrativa con el sistema inspirado en el Ombudsman, lo cierto es que, después de algunos años de funcionamiento, se ha comprobado que el Médiateur se ha alejado del modelo del Ombudsman, al limitarse a un papel de «intercesor» o «mediador» sin intentar erigirse en protector o defensor de las libertades públicas. Evidentemente, por esta misma razón también se aleja de nuestro DP, lo que significa que, salvadas quizá algunas experiencias extranjeras con valor ejemplar para nosotros, la tarea que se impone a los especialistas de nuestro país en relación con el problema que nos ocupa es de gran responsabilidad por lo que tiene de innovador $y$, por ello, de arriesgado.

Lo cierto es que, independientemente de la opinión que pueda tenerse acerca de la funcionalidad o disfuncionalidad de una figura inspirada en el Ombudsman, la Constitución española la ha introducido, y hay que pensar que no se trata de un tributo a la moda o de un planteamiento falso; antes al contrario, que con esta institución se pretende, entre otros fines, llenar esa laguna de que nos habla Bassols Coma. No se trata, a mi juicio, de elevar panegíricos o de repartir condenas apocalípticas como muchas veces se ha hecho frente a este mismo problema.

En un Estado como el liberal, en el que los servicios prestados por la Administración eran escasos, quizá era suficiente el autocontrol de la Administración y el eventual y posterior control jurisdiccional complementado con el control político del Parlamento sobre el Gobierno. Hoy, sin perder de vista que la misma justicia administrativa, como señala Bassols, es un producto histórico y que por ello «precisa de adaptarse a las cambiantes circunstancias sociales e ideológicas para hacer frente a los nuevos retos que le lanza el poder político en su constante lucha por lograr áreas inmunes»; sin perjuicio de ese perfeccionamiento deseable de la justicia administrativa, parece necesario incorporar nuevos instrumentos institucionales de vigilancia de la Administración, y más si estos instrumentos mantienen un contacto directo con las Cortes. Se trataría, por tanto, como concluye el propio Bassols, de armonizar y articular todos los medios existentes de control sobre la Administración.

En relación con las Cortes, en la medida grande o pequeña en que el DP se relacione con éstas en su labor de supervisión de la actividad de la Adminis-

${ }^{12}$ Cfr. M. Bassols Coma, Consideraciones sobre los controles extrajudiciales de la Administración: en torno a la reforma del «Médiateur» francés, RAP, núm. 82, 1977, pág. 382. 
tración, es indudable que la introducción de la institución es positiva por cuanto puede reforzar la capacidad de las asambleas para seguir más de cerca y en detalle el modo cómo el Gobierno y la Administración interpretan y aplican la ley. Desde el momento en que el Derecho hoy no se limita a crear un orden en el que pueda encuadrarse la acción de las fuerzas económicas y sociales, sino que actúa en medio de tales fuerzas y persigue objetivos concretos de política económica, social, etc., el control de las normas subordinadas a la ley se transforma en un control sobre la funcionalidad o disfuncionalidad de tales normas en relación con los objetivos perseguidos por la ley ${ }^{13}$. Esto va a exigir, además del control jurisdiccional tradicional, el concurso de nuevos sistemas de control sociales e institucionales. Entre estos últimos, el de las mismas Cortes, como la institución más representativa, y el del DP por su contacto estrecho con los ciudadanos.

En relación con los ciudadanos, el hecho de que se ponga a su disposición un nuevo medio de defensa de los derechos y libertades no puede sino reforzar la legitimación del régimen democrático en que ello es posible.

En todo caso, en la medida en que mediante la institución del DP se pretende complementar el control sobre la Administración que lleva a cabo la justicia administrativa, sería interesante contemplar algunos de los aspectos en que parece posible esta complementación. De la justicia administrativa se ha criticado fundamentalmente su carácter meramente individualista y subjetivo que puede condicionar sus posibilidades frente a la actividad administrativa eminentemente social.

Una regulación que admita el acceso no exclusivamente individual al DP puede convertir a éste en un complemento importante de la justicia administrativa, especialmente en lo que atañe a la defensa de intereses difusos o colectivos. Además, el hecho de que el DP tenga la posibilidad de actuar de oficio, como parece desprenderse del artículo 54, le exime de las limitaciones que conlleva el carácter no automático del control jurisdiccional.

También se ha considerado que el DP podría ocuparse de la vigilancia de determinadas prácticas viciosas, a veces corrientes en la Administración, y de eventuales faltas de ética, es decir, actuaciones que constituyen un campo que, por su propia naturaleza, se escapa fácilmente de la actividad de la jurisdicción contencioso-administrativa ${ }^{14}$. Otros autores insisten en esta misma vía, señalando que en nuestras latitudes la institución inspirada en el Ombudsman debería indicar su atención preferentemente a los casos que caen dentro del concepto, un tanto ambiguo, de maladministration, y que comprendería, además de las actuaciones ya señaladas, las posibles disfunciones propias de los mismos procedimientos administrativos, cada día más complejos ante la cantidad de intereses concurrentes que deben reducirse a unidad por la vía de la ponderación ${ }^{15}$.

La delimitación de la competencia del DP y, en concreto, la interpretación

${ }^{13}$ Cfr. García Pelayo, Las transformaciones del Estado contemporáneo, Alianza Editorial, Madrid, 1977 , págs. $65-66$.

${ }_{14}$ O. Alzaga, op. cit., pág. 355.

${ }^{15} \mathrm{Cfr}$. G. Zagrebelsky, Problemi costituzionali sulla nomina di un comisario parlamentare in Italia, en C. Mortati, L'Ombudsman (Il difensore civico), UTET, Turín, 1974, página 152. 
del término Administración, cuya actividad es objeto de supervisión, puede plantear nuevos problemas. Así, por ejemplo, cabe preguntarse si el DP tendrá competencia para supervisar las actividades de las empresas públicas o incluso de aquellas empresas privadas que, mediante la fórmula de contratos con la Administración, desarrollan funciones de carácter público. Quizá sea interesante a este respecto la solución adoptada en Francia, donde la competencia del Médiateur se determina no en base a un criterio orgánico, sino en función de un criterio material, basado en el concepto de servicio público ${ }^{16}$.

\section{B) El Defensor del Pueblo y el principio jerárquico de la Administración.} Una de las circunstancias que, como vimos, propiciaron el nacimiento del Ombudsman sueco fue la separación entre el Gobierno y la Administración, que implicaba la inexistencia de continuidad jerárquica entre ambos entes. En virtud de esta peculiar situación, una vez introducido el Justitieombudsman, el Parlamento tenía la posibilidad de vigilar a la Administración, no a través del Gobierno, sino mediante la original institución del Ombudsman.

En nuestras latitudes y, en concreto, en el sistema de gobierno parlamentario español el esquema es distinto. En primer lugar, la Administración se rige en base a un principio jerárquico, recogido en la Constitución (art. 103), que implica, en última instancia, que es el Gobierno quien dirige y controla la Administración (art. 97). De acuerdo con este modelo, las Cortes tienen la posibilidad de vigilar a la Administración mediante el control que pueden ejercer sobre el Gobierno. Los medios de información parlamentarios, como las preguntas e interpelaciones, e incluso la posibilidad que tienen las Cortes de reclamar la presencia de los miembros del Gobierno (art. 110) encajan en el esquema anteriormente expuesto.

No obstante, la misma Constitución prevé excepciones al anterior esquema, de manera que las Cortes pueden recabar información acerca de problemas administrativos sin necesidad de acudir al Gobierno, aunque el control final siga estando enfocado sobre este último. Tal es el caso de las comisiones de investigación, previstas en el artículo 76, de la posibilidad que tienen las Cortes, según el artículo 109, de reclamar la información que precisen de cualesquiera autoridades del Estado y del Tribunal de Cuentas, previsto por el artículo 136, y que «dependerá directamente de las Cortes y ejercerá sus funciones por delegación de ellas».

La institución del DP se sitúa en esta última perspectiva, si bien no cabe su identificación con un simple instrumento a disposición de las Cortes. Es decir, el DP, de acuerdo con la figura que nos proporciona el Ombudsman escandinavo, podrá supervisar la actividad de la Administración yendo directamente a sus distintos servicios y funcionarios, sin tener por qué utilizar el camino oblicuo que pasa por el Gobierno. Y, lógicamente, la presencia de una institución inspirada en el Ombudsman no deja de tener consecuencias sobre el principio jerárquico de la Administración.

Pero antes de pasar al análisis de esta incidencia, puede resultar conve-

${ }^{16}$ Véase A. Gil Robles y Gil Delgado, El control parlamentario de la Administración (El «Ombudsman»), IEA, Madrid, 1977, pág. 159. 
niente un breve examen del mismo principio jerárquico de la Administración en la actualidad. Pues ocurre que si bien a nivel formal el principio permanece, de hecho, no sucede enteramente así. En concreto, es preciso tener en cuenta cómo ya desde la misma Revolución francesa la Administración se dibuja como un poder autónomo que permanece mientras los Gobiernos cambian, con una incidencia real en las decisiones del Estado, al menos en los niveles tecnocráticos superiores, y con una tendencia hacia un «aislamiento corporativo» y a configurarse como «ordenamientos separados, impermeables $o$, al menos, refractarios a todo tipo de interferencia o control externo» ${ }^{17}$. En estas condiciones sucede que el Gobierno o los ministros son a veces incapaces de controlar a la Administración, porque, como indica Zagrebelsky, el ministro está sólo teóricamente en el vértice de la Administración, o porque puede estar interesado en no enemistarse con los funcionarios de la misma. Aun en estas condiciones, los ministros y el Gobierno son responsables ante el Parlamento de los errores o ilegalidades de la Administración en base al principio de jerarquía, formalmente en vigor. $\mathrm{Y}$ en muchos casos el Parlamento utiliza sus medios de información al objeto de tener una base sobre la que exigir las responsabilidades correspondientes. Aunque, también es cierto, se puede dudar en muchos casos de la eficacia de las preguntas e interpelaciones como medio de conseguir la información adecuada, y el recurso a la encuesta parlamentaria cabe solamente en problemas de gran alcance político o social, pero no en los múltiples problemas ordinarios que encuentra el ciudadano ante la Administración.

En estas circunstancias, el DP, como institución funcionalmente especializada en la supervisión de la actividad de la Administración, puede al menos complementar eficazmente los medios de control clásicos. Sin embargo, como hemos apuntado, también puede constituir una alteración del principio jerátquico en la medida en que, si no de responsabilidad, sí que cabe hablar de una cierta subordinación de los funcionarios a los criterios del DP.

En Francia, al crear en 1973 la figura del Médiateur, se intentó solucionar el problema haciendo depender la investigación del Médiateur sobre un funcionario de la autorización del ministro o autoridades públicas superiores jerárquicamente ${ }^{18}$. Pero, evidentemente, la solución francesa puede tener más o menos lógica desde el momento en que el Médiateur es nombrado por el Consejo de Ministros. No la tendría, evidentemente, en nuestro caso, en cuanto que son las Cortes quienes designan al DP.

La medida francesa que acabamos de evocar es demasiado tajante y evidente como para que pudiera defenderse en nuestro país. Pero alguien podría proponer medios más sutiles que condujeran a una situación similar a la francesa.

A este respecto, cabe señalar que una de las condiciones necesarias para el ejercicio del control es la información. Como veremos, la actitud del DP no es de control, sino que sirve de base para la actuación de otras instituciones con

${ }^{17}$ Zagrebelsky, op. cit., pág. 148.

${ }_{18}$ Bassols, op. cit., págs. 400-401, señala que la reforma del Estatuto del «Médiateur» de 1976 ha atenuado dicho principio jerárquico. 
competencias de control. Pero no cabe duda de que la eficacia e incluso la misma posibilidad de que lleve a cabo su misión depende enteramente de que pueda recabar una información oportuna y completa en relación con los asuntos de que se ocupe, lo que implica su acceso incluso a los documentos internos de la Administración. Por ello, cualquier intento de mediatizar la información del DP en aras del principio jerárquico podría poner en peligro la misma institución.

Por su relación estrecha con el principio jerárquico, el problema tampoco se plantea en Suecia, al contrario de lo que sucede en otros países en los que el mencionado principio tiene vigencia ${ }^{19}$.

En nuestro país la solución que se dé al problema parece que depende exclusivamente de la ley orgánica reguladora del DP, pues las diferentes disposiciones de la Constitución que se refieren a la publicidad en relación con la Administración, no afectan, en principio, al DP. Así, el artículo 105, que prevé una ley sobre estas cuestiones y que en su apartado $b$ señala ciertas limitaciones para acceder a los archivos y registros administrativos, afecta únicamente a los ciudadanos, mientras que el DP es una institución creada por la Constitución. Por otro lado, los artículos 76 y 109, que hacen referencia a la posibilidad de información de las Cortes y que, en principio, ignoran la estructura jerárquica de la Administración, afectan a la cámaras y comisiones parlamentarias, pero no al DP.

Lo que sí parece claro es que, cualquiera que sea la solución que se adopte, el DP, además de una discreción propia del cargo, tendrá la obligación jurídica de no divulgar temas que afecten «a la seguridad y defensa del Estado, la averiguación de los delitos y la intimidad de las personas», como, a sensu contrario, se desprende del artículo 105-b. Y esta obligación probablemente le acompañará incluso después del cese en el cargo.

El problema no es de fácil solución. En efecto, si al DP se le ponen unas limitaciones similares a las previstas en el artículo $105-b$, éste no podrá hacerse una idea completa de determinados asuntos. Por otro lado, en el supuesto de que el DP no tuviera ningún tipo de obstáculos a la hora de recabar información, se le trasladaría a él el mandato constitucional de no divulgar determinadas cuestiones y, por tanto, de no dar entera satisfacción a problemas que pudieran habérsele planteado. $\mathrm{Y}$, en este supuesto, podría sufrir merma la confianza necesaria del ciudadano en la institución. No obstante, parece que ésta sería la solución más aceptable, pues, además de con los ciudadanos, el DP está en relación con las Cortes. Y en todo caso, con respecto a los ciudadanos, convendría armonizar las necesarias limitaciones constitucionales con la no menos necesaria exigencia de que la opinión pública conozca lo que sucede en el interior de la Administración.

Parece, pues, conveniente que la solución general al conflicto planteado entre la competencia del DP con relación a la actividad de la Administración y el principio jerárquico de la misma se resuelva de modo que aquél no encuentre ninguna mediatización ni limitación derivada de dicho principio. En lo

19 Véase, por ejemplo, Dinamarca y República Federal Alemana, en Legrand, op. cit., páginas 240 y 269 , respectivamente. 
que respecta a las eventuales responsabilidades, $\sin$ ir $\tan$ lejos como a veces se ha propuesto, podría simultanearse una acentuación de la responsabilidad autónoma de los funcionarios con el mantenimiento del principio jerárquico simultaneado con el de responsabilidad ministerial.

Desde esta perspectiva, la supervisión del DP se extendería sobre cada uno de los funcionarios individualmente, así como sobre la Administración en su conjunto y, de rechazo, sobre el Gobierno. Además, a partir de las consideraciones anteriores pueden desprenderse dos importantes consecuencias desde la perspectiva del Gobierno o de los ministros.

En primer lugar, que el mismo Gobierno o los ministros perfeccionarían el control sobre sus propios funcionarios y sobre la Administración en general, al objeto de eludir la correspondiente responsabilidad ante las Cortes.

$\mathrm{Y}$ desde un punto de vista positivo, en la medida en que los objetivos del Gobierno fueran acordes con la función de defensa de los derechos y libertades encomendada al DP, el mismo Gobierno, así como cada uno de los ministros podrían encontrar en las investigaciones e informaciones de esta institución, más que elementos sistemáticamente perturbadores de sus actuaciones, un complemento valioso para llevarlas a cabo felizmente.

C) El Defensor del Pueblo y las Cortes Generales. El principio de responsabilidad parlamentaria. Según hemos visto ya, la Constitución encomienda al DP la función de defender los derechos comprendidos en el Título I y, como medio para el cumplimiento de esta función, le atribuye la potestad de supervisar la actividad de la Administración y la legitimación para interponer el recurso de inconstitucionalidad, además del de amparo.

Los distintos medios de actuación de que dispone el DP configuran una distinta posición institucional del mismo, hasta el punto de que podría hablarse de una institución mixta, en cuanto que, como ya hemos observado, su legitimación para acudir al Tribunal Constitucional determina que esta institución debe tener toda la independencia orgánica y funcional posible con respecto a las Cortes; $y$, como vamos a comprobar ahora, su potestad con referencia a la Administración le sitúa en una posición de relación estrecha, hasta cierto punto, con las Cortes y, desde luego, la subordina en una cierta medida a los poderes de las mismas ${ }^{20}$. El problema se centra ahora en determinar qué

${ }^{20}$ Esta configuración del Derecho penal le distingue, como ya hemos señalado, del Ombudsman escandinavo. Sin embargo, la novedad es relativa puesto que al Ombudsman militar de la República Federal Alemana también le encomienda la Ley Fundamental la defensa de los derechos fundamentales y el auxilio al «Bundestag»-art. 45b de la Ley Fundamental- si bien dentro del campo militar. No cabe una equiparación entre la figura alemana y el Derecho penal español. Pero resulta ilustrativo señalar cómo en la República Federal Alemana existe una opinión generalizada que habla de una doble posición del Ombudsman militar en un sentido paralelo al que hemos indicado para el Derecho penal. Legrand, op. cit., págs. 266 y 268, participa de este análisis; en cambio, E. Lohse, op. cit., pág. 171, se inclina por una interpretación contraria que considera al Ombudsman militar en tanto que «órgano subordinado... del 'Bundestag'». En todo caso, a partir de la posición sistemática - es el argumento principal que utiliza Lohse- que ocupa el artículo 54 de nuestra Constitución y de la legitimación para interponer el recurso de inconstitucionalidad, en España sería muy difícil mantener una interpretación similar a la de Lohse. 
construcción del DP en relación con las Cortes sería lógica en función del nivel de actuación, derivado de su potestad, para supervisar la actividad de la Administración.

A este respecto, el artículo 54 parece sugerir determinados criterios inspiradores de la relación del DP con las Cortes. El citado artículo, en efecto, califica al DP como «alto comisionado de las Cortes Generales», y después de señalar que «podrá supervisar la actividad de la Administración», le indica que deberá dar cuenta a las Cortes Generales, siendo lógico suponer que esta rendición de cuentas se refiere a las actividades del DP en relación con la Administración. Como también parece lógico deducir del artículo 54 que el calificativo de alto comisionado se le atribuye al DP en cuanto defiende los derechos y libertades mediante la supervisión de la actividad de la Administración. Pensar que el DP actúa como comisionado de las Cortes cuando interpone un recurso de inconstitucionalidad es, cuando menos, ilógico.

Ahora bien, el calificativo de «comisionado» parece encerrar una cierta idea de subordinación que puede desarrollarse en un aspecto negativo (b), en el sentido de que el comisionado no interferirá las actividades resultantes de los poderes de las Cortes y, en un aspecto positivo (a), del que se puede discutir su sentido.

a) Una de las manifestaciones positivas de esta subordinación nos la muestra el mismo artículo 54, cuando obliga al DP a dar cuenta a las Cortes de sus actividades en relación con la Administración. Esta obligación suele materializarse en el Derecho comparado en un informe general anual. Y la obligación de este informe nos pone en relación con otra manifestación de subordinación, que aparece en el Derecho comparado y que, como hemos señalado, podría también introducirse en nuestro país. Se trata de la eventual revocación del DP por parte de quien lo designó. La presentación del informe general anual ante las Cortes brinda una ocasión especialmente oportuna para revocar al titular o confirmarlo implícita o explícitamente en su labor.

De todas formas, como parece desprenderse de la Constitución, además de este posible informe anual, en cualquier momento las Cortes podrán reclamar del DP todo tipo de informes concretos sobre sus actuaciones y resultados de las mismas en relación con la actividad de la Administración.

Otra interpretación más amplia de la subordinación podría cifrarse en la posibilidad de que el DP, además de las obligaciones anteriores, debería llevar a cabo mandatos procedentes de las Cortes.

A este respecto, el Derecho comparado nos ofrece dos modelos fundamentales. Un primer modelo nos muestra al Ombudsman como instrumento a disposición del Parlamento para controlar a la Administración. A su vez, este modelo presenta diversas variantes en los distintos países. Por ejemplo, en Noruega la subordinación del Ombudsman al Storting se concreta en que la competencia del primero no depende de su libre discreción, sino que es el Storting quien decide en los casos dudosos. Por otro lado, el Storting puede someter ciertas cuestiones al examen previo del Ombudsman, quien queda obligado a dar una respuesta a la petición ${ }^{21}$. El carácter de dependencia que

${ }^{21}$ Véase Legrand, op. cit., págs. 257 y sigs. 
muestra este modelo resulta más acusado en el Ombudsman militar alemán, sin perjuicio del doble nivel de actuación, ya señalado, que presenta esta institución. En todos estos casos el Ombudsman aparece principalmente como una longa manus del Parlamento.

De acuerdo con el segundo modelo ofrecido por el Derecho comparado, el Ombudsman, aunque dentro de la órbita parlamentaria, realiza prácticamente todas sus actuaciones de modo autónomo. El ejemplo típico es el sueco quien, salvo casos particulares —acusación de ministros y altos funcionarios ante el Alto Tribunal- nunca actúa a las órdenes del Riksdag. Incluso, como señala Legrand, los poderes del Ombudsman -es el caso de la aparición de los erinringar, que veremos más adelante- han seguido un desarrollo evolutivo, al margen de la ley que regula al Ombudsman, de acuerdo con este principio de autonomía.

En cuanto a nuestro país, en principio no parecería oportuno que las Cortes pudieran encomendar al DP la investigación de asuntos concretos, pues, además de que para eso están las comisiones de investigación, dicho mandato, al depender de la mayoría parlamentaria - a no ser que también se establecieran mayorías cualificadas para ello- anularía hasta cierto punto las cautelas que hubieran podido preverse para el nombramiento del titular de la institución. En todo caso, cabría que las Cortes trasladaran al DP algunas de las peticiones que los ciudadanos pudieran dirigirles $\mathrm{y}$, en esta hipótesis, el DP podría tratarlas o archivarlas según su criterio.

De todas formas, parecería conveniente que ambas Cámaras atribuyeran a una de sus respectivas comisiones la tarea de asegurar una relación permanente con el DP, sin perjuicio de las competencias que el artículo 54 atribuye a las Cortes en su conjunto. $\mathrm{Y}$ a este respecto, si tenemos en cuenta la función del DP y el carácter fundamentalmente jurídico de sus actuaciones e informes, la más idónea para esta labor sería la Comisión Constitucional.

No obstante, y aun cuando convendría retener determinadas consecuencias positivas de la subordinación del DP con respecto a las Cortes, a la hora de regular este aspecto la ley orgánica debería salvar ciertas limitaciones que parecen derivarse de la Constitución.

Así, en primer lugar, no habría que perder de vista la diferencia de enfoques que pueden animar en un momento dado a las Cortes y al DP. Mientras que éste último, en principio, tiene como fuentes fundamentales de criterio a la Constitución y a la ley, las Cortes, al contrario, se inspiran ampliamente en criterios de oportunidad. Por otro lado, los enfoques funcionales de una y otra institución son también distintos. Así, mientras que frente al quebrantamiento de un derecho fundamental de un ciudadano particular, el DP deberá consagrar toda su atención al caso, pues tal es su función, las Cortes pueden estar más inclinadas a interesarse por problemas de tipo general.

En segundo lugar, es previsible que determinadas actuaciones del DP en relación con la actividad de la Administración culminen, no en un informe ante las Cortes, sino en un recurso ante el Tribunal Constitucional.

En tercer lugar, del artículo 54, que dispone que el DP «podrá supervisar la actividad de la Administración», cabe deducir que al DP le asiste la posibilidad de actuar de oficio o, cuando menos, a instancia de alguien - los 
ciudadanos- que no sean las Cortes. Otra interpretación chocaría con el razonamiento anterior en relación con los recursos ante el Tribunal Constitucional; además de que haría prácticamente inútil la existencia misma del DP en relación con la potestad que analizamos, pudiendo haberlo sustituido la Constitución por una comisión parlamentaria de investigación permanente.

Finalmente, dado que el DP constituye una institución especializada por su función, el éxito de la misma depende en gran medida de que la organización de la institución, sus técnicas de trabajo y las investigaciones concretas estén dirigidas autónomamente por el propio titular quien, además de que será un especialista competente, dirigirá sus pasos en razón de la función que se le atribuye sin la mediatización de otros condicionamientos como, por ejemplo, de oportunidad.

b) Veamos ahora el aspecto negativo en que puede desarrollarse la idea de subordinación que encierra el calificativo de comisionado parlamentario. En este sentido parece que el DP no deberá interferir las actividades que resultan de los poderes de las Cortes. Entra aquí de lleno la posibilidad de que el DP interfiriera el mecanismo de responsabilidad del Gobierno ante las Cortes, y que por ello pudiera quedar desdibujada la relación dialéctica entre mayoría y oposición. Lo expresa claramente Mitchell: «Si el ministro acepta la recomendación (del Ombudsman), habrá sustancialmente una transferencia de responsabilidad ministerial. Además debe recordarse que esta doctrina es el fundamento necesario del conflicto esencial de los partidos» ${ }^{22}$.

Desde el punto de vista del Derecho comparado, Dinamarca ha resuelto satisfactoriamente el problema. En este país en el que los ministros son, al mismo tiempo que miembros del Gobierno, jefes jerárquicos de una rama de la Administración, se parte de la base de que una prohibición al Ombudsman de abordar problemas que le condujeran hasta el ministro correspondiente, implicaría "vaciar de toda sustancia» su competencia de vigilar las actividades de la Administración ${ }^{23}$. Por ello, la potestad del Ombudsman se extiende sobre la actividad de los ministros como sobre la de cualquier otra persona al servicio del Estado ${ }^{24}$. No obstante, el Ombudsman danés encuentra dos limitaciones en esta tarea: en primer lugar su actividad de supervisión se reduce a las actuaciones propiamente administrativas de los ministros y, en segundo lugar, no puede actuar en caso de intervención previa del Parlamento. Ante la primera limitación, cuya interpretación puede ofrecer dificultades, el Ombudsman entiende que, en todo caso, la cuestión cobra tintes políticos desde el momento en que sobre el asunto existe una declaración del ministro ante el Parlamento o ante una comisión parlamentaria ${ }^{25}$. En relación con la

22 J. D. B. Mitchell, Las propuestas del «Ombudsman» son inaplicables, en D. C. Rowat, op. cit., pág. 361.

${ }_{23}$ Cfr. Legrand, op. cit., pág. 209.

${ }^{24}$ Véase art. 4 de la ley danesa relativa al Ombudsman de 11 de junio de 1954, reformada en 1959 y 1970.

${ }_{25}$ Legrand, op. cit., pág. 213, señala la analogía de esta situación con la francesa donde los actos concernientes a las relaciones entre el Gobierno y el Parlamento entran en la categoría de «actos de gobierno» no controlables jurisdiccionalmente. Evidentemente, esta consideración puede ser especialmente útil en nuestro país. 
segunda limitación, de hecho se interpreta en un sentido restrictivo, puesto que si las circunstancias lo exigen el Ombudsman no tiene inconveniente en iniciar o proseguir una investigación sobre la actividad de un ministro en relación con aspectos del problema que quedaron sin explicar ante el Parlamento y que por ello éste no pudo pronunciarse sobre los mismos. Este equilibrio entre el Ombudsman y el Parlamento que se desprende de la construcción danesa nace de la subordinación, en su aspecto negativo, del primero con respecto al segundo.

Pero, si bien esta solución podría trasladarse a nuestro país, sería preciso matizarla ya que aquí el problema se complica dada la legitimación del DP para acudir ante el Tribunal Constitucional que le coloca en posición de poder supervisar la actividad legislativa. Además, el DP no deja de estar legitimado para interponer el recurso de amparo por una declaración del ministro ante las Cortes o porque éstas examinen el caso. De todas maneras, en estas cuestiones, la única vía que quizá quede al DP consistiría en ampararse en el rigor jurídico de su razonamiento.

De lo dicho anteriormente cabría sacar la conclusión de que la existencia del DP podría interferir los poderes de control de las Cortes en relación con el principio de responsabilidad ministerial. Pero, lo cierto es que las eventuales interferencias que pudieran producirse nacen de hechos objetivos, ajenos a la institución que comentamos, como son la existencia misma de un Tribunal Constitucional y de su legitimación para acudir ante él.

De todas formas, la posible conclusión anterior podría matizarse si atendemos a otros posibles aspectos que presenta la actividad del DP en relación con la Administración. Así, cuando la responsabilidad derivada de un asunto pueda afectar a un ministro o al Gobierno, el DP, debido a la independencia política de que en principio goza, podría paliar las desventajas que pueden surgir del hecho de que el Gobierno esté firmemente apoyado por la mayoría parlamentaria. Legrand señala cómo aunque no se tratara más que de una reacción puramente moral se estarían reforzando otras formas de responsabilidad ministerial ${ }^{26}$. Por otro lado, si en España se dispusiera una construcción similar a la danesa, y salvando las consecuencias derivadas de la legitimación del DP para entablar los citados recursos, las Cortes siempre tendrían la posibilidad de arrebatar el problema al DP mediante la utilización de sus propios mecanismos de investigación. Además, ya señalábamos en el epígrafe anterior cómo, si bien el principio jerárquico de la Administración conserva toda su vigencia a nivel formal, de hecho se da la circunstancia cada día más acusada de que el Gobierno no llega a todos los rincones de la Administración. Asimismo, también es conocida la creciente incapacidad fáctica de los Parlamentos - falta de información, juego mayoría-oposición, criterios no de legalidad sino de oportunidad, la gravedad que suelen encerrar sus medidaspara controlar debidamente al ejecutivo.

Por ello, quizá no le falte razón a Legrand cuando señala que la responsabilidad ministerial no es más que un «cebo engañoso» en relación con las

${ }^{26}$ Legrand, op. cit., pág. 217. 
decisiones de menor importancia ${ }^{27}$. Y es precisamente en el terreno de estas decisiones menores donde el DP podría mostrar su utilidad, primeramente con más frecuencia, puesto que los grandes problemas, como tales, suelen ser excepcionales, $y$, en segundo lugar sin levantar suspicacias especiales ya que son estas cuestiones las que más fácilmente pueden pasar desapercibidas al ministro y a las Cortes.

\section{LA AUTORIDAD DEL DEFENSOR DEL PUEBLO}

La supervisión de la actividad de la Administración puede plantear problemas específicos. Así, ante la eventual negativa de un funcionario a comparecer ante el DP o a proporcionarle la información requerida, cabe preguntarse si éste tendrá en sus manos las medidas coactivas necesarias para poder llevar a cabo su misión.

El problema aquí expuesto es distinto del que nos planteábamos en relación con las posibilidades de información del $\mathrm{DP}$ aùn a riesgo de menoscabar el principio jerárquico de la Administración. No obstante, existe una relación entre ambas cuestiones. Así, el Médiateur francés carece de poderes coactivos en relación con la Administración para desarrollar su labor ya que, en definitiva, depende de las propias autoridades administrativas el que los funcionarios faciliten el trabajo del Médiateur. En cambio, según se desprende del Derecho comparado, el Ombudsman tiene a su disposición diversas medidas coactivas en relación con la Administración, que se concretan, o bien en la posibilidad de imponer multas - número 10, ley sueca de 29 de diciembre de 1967-, o, lo que es más corriente, en la asimilación de los poderes del Ombudsman a los de un juez de instrucción mediante la remisión de esta cuestión a las leyes procesales —número 7, ley noruega de 22 de junio de 1962; artículo 7, ley danesa, cit.; númeto 8-2 de la ley de Gran Bretaña de 22 de marzo de 1967, etc.

En cuanto a nuestro país, parece que de la Constitución pueden desprenderse algunos criterios al respecto. En la medida en que se encomienda al DP una función concreta y una serie de medios encaminados al desarrollo de dicha función, se podría concluir que de manera implícita la Constitución reconoce asimismo al DP la posibilidad de utilizar las medidas necesarias para ello. Por otro lado, puesto que el DP depende en cuanto a su formación de las Cortes, parece también lógico que dichas medidas sean externas en relación con la Administración. No obstante, lo que quizá no sea posible extraer de la Constitución, como imperativo lógico derivado del artículo 54, es el grado de coactividad que deba acompañar a tales medidas. Aunque, si tenemos en cuenta que la eficacia en el cumplimiento de su importante función y el consiguiente enraizamiento popular de la institución pueden depender en gran medida de este extremo, un criterio de oportunidad tendería a dotar al DP de todas las medidas coactivas que la Constitución permita. Y a este respecto, las condiciones previstas para el desarrollo de las encuestas parlamentarias o

${ }^{27}$ Legrand, op. cit., pág. 216, nota núm. 24. 
de las funciones del poder judicial podrían apuntar las directrices informadoras convenientes.

Cabe preguntarse ahora cuál es el mecanismo último que asegurará la defensa de los derechos y libertades, así como el papel que corresponde al DP en este mecanismo.

Pero, a fin de responder a esta cuestión, es preciso que delimitemos de modo suficiente la naturaleza de esta institución ${ }^{28}$. Y para ello quizá baste con que, yendo por el camino fácil de la delimitación negativa, señalemos que a partir de la construcción que parece desprenderse de la Constitución, el DP es una institución que carece de competencias de control. Y para ello partimos de una noción de control que incluiría en su estructura un juicio del controlante acerca de la normalidad del modo de actuar o del modo de ser de los operadores jurídicos que conduciría, en caso de valoración desfavorable, a la adopción de una medida obstaculizadora del comportamiento o de la situación organizativa anormales.

Parece claro que los medios de que disfruta el DP para el cumplimiento de su función no encajan en los elementos estructurales de la noción de control señalada, puesto que, si bien el DP puede formarse un juicio acerca de la normalidad o anormalidad del comportamiento de los operadores jurídicos que caen en su ámbito, la Constitución no le proporciona, al menos directamente, la posibilidad jurídica de adoptar medidas obstaculizadoras. El artículo 54 parece dar a entender que las posibles medidas correrían a cargo de las Cortes y el artículo 162 deja bien claro que el DP está legitimado para acudir ante el Tribunal Constitucional, lo que implica que las medidas obstaculizadoras correspondientes están en manos de dicho Tribunal. Y por esta razón, los mismos juicios desfavorables que puede formarse el DP en el curso de sus actuaciones no llevan necesariamente hacia la adopción de eventuales medidas obstaculizadoras, puesto que éstas escapan de su ámbito, sino que, en todo caso, pueden servir de base para que otras instituciones dotadas de competencias de control vean facilitada su labor -en el caso de las Cortes- o que se pongan en movimiento - es el caso del Tribunal Constitucional-.

Así pues, se podría concluir que el DP es una institución que carece de competencias de control pero que efectúa labores previas al control que pueden servir de base para la actuación de otras instituciones dotadas de tales competencias.

Ya lo hemos visto en relación con las Cortes y con el Tribunal Constitucional. Pero también se puede prever que las actuaciones del DP podrán constituir una base para que la propia Administración ponga en marcha sus propios mecanismos internos de control por propia iniciativa o a instancia de los ciudadanos informados convenientemente por el DP, o para que estos mismos ciudadanos acudan a los Tribunales. Asimismo, independientemente de su incidencia sobre las instituciones dotadas de competencias de control, las ac-

${ }^{28}$ A. Legrand, op. cit., págs. 282-283, indica en relación con el Ombudsman sueco que sus actividades no tienen carácter jurisdiccional puesto que puede actuar de oficio y sus decisiones no tienen la fuerza de la cosa juzgada; Zagrebelsky, op. cit., págs. 152-153, habla de un papel «de alguna manera político» del Ombudsman en general; también es conocido el calificativo de «magistratura de persuasión» que le ha atribuido A. la Pergola. 
tuaciones del DP, dada la publicidad de que habrán de estar rodeadas, afectarán en mayor o menor medida a la opinión pública, con las consecuencias, electorales o de otro tipo, que pudieran derivarse de ello.

Quizá ahora podamos responder, al menos en parte, a la pregunta inicial de cuál será el mecanismo último que permita la salvaguardia de los derechos y libertades y el papel que en ello juega el DP, diciendo que a esta institución la corresponde una previa labor instrumental, informativa y motora, y que la salvaguardia definitiva de los derechos y libertades corresponde a otras instituciones y, en último término, al Tribunal Constitucional.

Pero la conclusión anterior no puede constituir una respuesta acabada a la pregunta formulada inicialmente. A este respecto, cabe remitirnos al desarrollo histórico del Ombudsman sueco para comprobar cómo, en virtud de una construcción similar en lo esencial a la de nuestro $\mathrm{DP}^{29}$, surgía en manos del Ombudsman una autoridad que le permitía formular recomendaciones a la Administración -erinringar - que, aunque jurídicamente no revistieran carácter obligatorio, de hecho, lo adquirían ante la amenaza de utilización por el Ombudsman de los medios que en derecho le correspondían. Es decir, a las competencias inicialmente atribuidas al Ombudsman que implicaban la realización de labores previas al control, por la vía de hecho se añadía a modo de fuerza resultante una nueva de carácter autónomo ${ }^{30}$.

Sobre si la institución española gozará o no de una competencia autónoma en relación con la Administración, similar a la del Ombudsman sueco, será la ley, y en todo caso la experiencia, quien dilucide la cuestión. Aunque parece evidente que, al menos de modo negativo, la Administración tenderá a observar los criterios que pudieran derivarse de los informes del DP. Pero independientemente de ello, el origen constitucional del DP, sus relaciones con las Cortes y con la opinión pública otorgan a esta institución una autoridad de carácter autónomo cuya consecuencia más clara podría manifestarse de modo que su sola presencia y el riesgo de incurrir en sus críticas produjera un funcionamiento de la Administración más respetuoso con los derechos y libertades de los ciudadanos.

$Y$ en este punto parece necesario dar cuenta de un peligro que podría derivarse de la existencia del DP en relación con la funcionalidad de la Administración, en el sentido de que la presencia de aquél, en lugar de constituir un incentivo para la buena marcha de la Administración se convirtiera en un inconveniente que indujera a los funcionarios a una interpretación excesivamente formalista de las disposiciones normativas con el fin de evitar la actuación del DP. En relación con este problema posible, Zagrebelsky da un enfoque correcto de la institución al señalar que debe constituir «un colaborador crítico de la Administración y no un órgano colocado en posición dia-

${ }^{29}$ Recordemos no obstante que el Ombudsman en Suecia puede intentar acciones penales contra los funcionarios. Recordemos también cómo una de las innovaciones que presentaba el Ombudsman danés afectaba precisamente a este punto, lo que implicaba el riesgo de "transplantar un árbol al que se le habían cortado las raíces»; véase Legrand, $o p$. cit., págs. 228-229.

${ }_{30}$ Posteriormente la ley reconocería esta nueva facultad; véase Legrand, op. cit., páginas 486 y sigs. 
léctica cuya sola intervención o riesgo de la misma tuviera efectos paralizantes» ${ }^{31}$.

En nuestro caso concreto, el artículo 54 es terminantemente claro al respecto cuando indica al DP que su función estriba en la defensa de los derechos y libertades comprendidas en el Título I. Sólo después señala que, a tal fin, podrá supervisar la actividad de la Administración, lo que implica que el ejercicio de esta potestad deberá realizarse con la mirada puesta en la función asignada. Por ello, si bien es cierto que la investigación del DP podrá afectar a los funcionarios individualmente, no lo es menos que también podrá tener una incidencia, a veces exclusiva, sobre la Administración en cuanto tal. Así, en muchos casos la supervisión del DP podrá dar como resultado que el incumplimiento de determinadas obligaciones de la Administración correspondientes a derechos públicos subjetivos no pueden imputarse a los funcionarios del servicio en cuestión sino a la carencia de los medios imprescindibles para ello.

Por otro lado, ante eventuales críticas de los ciudadanos en contra de un funcionario, la interposición del DP entre ambas partes siempre constituirá una garantía de respeto a los derechos del funcionario además de que, en determinados casos, su actuación esclarecedora podrá convertirle en protector de los intereses de un funcionario criticado injustamente. Desde otro punto de vista, sería preciso tener en cuenta que quizá el DP, a semejanza de lo que ocurre en el caso del Ombudsman típico, operará conforme a un procedimiento rápido y flexible ${ }^{32}$ lo que, al mismo tiempo que una ventaja, puede constituir un menoscabo de las garantías derivadas de los procedimientos legales tradicionales. Al objeto de paliar tal inconveniente, que si diera lugar a un atropello de los derechos de un funcionario constituiría, dada la función del DP, una trágica incongruencia, serían necesarias algunas cautelas como, a modo de ejemplo, la de evitar la publicidad de las actuaciones preliminares del DP hasta que no emitiera su informe final, sin perjuicio de otras garantías que podrían ponerse en manos de los funcionarios.

\section{EL DEFENSOR DEL PUEBLO Y LOS CIUDADANOS}

En la introducción a este trabajo veíamos cómo el Ombudsman sueco nacía ligado al derecho de petición. Hoy, en Suecia, aun cuando gran parte de la eficacia del Ombudsman depende fundamentalmente de sus investigaciones periódicas y programadas a los distintos servicios administrativos, el grueso de su actividad aparece guiada por el «capricho» de las peticiones ciudadanas. $\mathrm{Y}$ en Dinamarca, donde el contacto personal del ciudadano con el Ombudsman es corriente dadas las pequeñas dimensiones del país, ocurre el mismo fenómeno con mayor intensidad todavía ${ }^{33}$.

El problema de si el acceso del ciudadano al Ombudsman debe ser directo o indirecto comienza a plantearse cuando en Gran Bretaña y Francia se

31 Zagrebelsky, op. cit., págs. 149-150.

32 Véase O. Alzaga, op. cit., pág. 354.

${ }^{33}$ Véase Legrand, op. cit., págs. 132 y 229 y sigs. 
intenta la aclimatación de instituciones más o menos inspiradas en el Ombudsman. En estos dos países el acceso de los ciudadanos a la institución se realiza a través de los parlamentarios que son quienes reciben las peticiones y las trasladan o no, según su criterio, al titular.

Para justificar esta innovación se aducen fundamentalmente dos razones. Por un lado, que el acceso directo del ciudadano a la institución perjudicaría el contacto de los representados con los parlamentarios, además de que se privaría a éstos de una posible acción de denuncia contra el Gobierno. Por otra parte, se señala que mientras el acceso directo es posible en países de población reducida, como los nórdicos, en otros, con un importante número de habitantes, el acceso indirecto proporciona un filtro necesario para el funcionamiento de la institución que, de otra manera, ante el elevado número de peticiones previsibles, se vería obligado a organizar otro gran aparato burocrático.

Frente a estos argumentos, se afirma que si el éxito de la institución se debe en gran parte a la relación directa entre ésta y el ciudadano, no cabe duda de que una mediatización parlamentaria puede tener una incidencia negativa en el desarrollo de la institución. Por otra parte, si se tiene en cuenta que el Ombudsman está llamado a resolver quejas de carácter administrativo, quizá el tratamiento más adecuado de dichas quejas no sea el de la publicidad política previa a la solución de caso inherente a las preguntas parlamentarias, sino por el contrario la investigación detallada y en profundidad del Ombudsman. Además de que si lo que realmente se busca es la solución del caso, el método informal y personal del Ombudsman puede ser más eficaz en estas cuestiones que la denuncia política solemne.

Antes de plantear el problema con respecto a nuestro país, sería preciso hacer algunas consideraciones previas. En primer lugar, cabría tratar el argumento en relación con el mayor o menor número de habitantes de un país y que puede revestir gran importancia desde el momento en que en Suecia, donde ha nacido y se ha desarrollado el Ombudsman y que no sobrepasa los ocho millones de habitantes, ha sido necesario crear varios titulares de la institución. Sin embargo, parece que en nuestro caso pueden existir bases para una solución del problema pues, sin perjuicio de que pudiera acudirse en un determinado momento a DP sectoriales, la organización territorial del Estado en comunidades autónomas podría ofrecer una vía de solución. En segundo lugar, también sería necesario considerar que, dada la ausencia de tradición parlamentaria reciente en nuestro país, es probable que tampoco se plantee de la misma manera aquel primer argumento en contra del acceso directo que, además de otras posibles razones, tiene su raíz en la rica gama de relaciones entre parlamentarios y ciudadanos que en el caso de Gran Bretaña y Francia se ha ido forjando a lo largo de una experiencia democrática prolongada. Lo que no obsta para que, precisamente mediante el acceso indirecto al DP, pudiera facilitarse en España el nacimiento de tales relaciones entre ciudadanos y parlamentarios.

Pero después de estas consideraciones, cabe señalar que no parece que sea posible la adopción de la fórmula de acceso indirecto tal como tiene lugar en Gran Bretaña y en Francia, donde los parlamentarios, según su criterio, tras- 
ladan o no las peticiones al comisario o al Médiateur, puesto que nuestra Constitución, como ya hemos señalado, parece prefigurar un DP que puede actuar de oficio y que, o bien se relaciona directamente con los ciudadanos, o bien, en todo caso, recibe todas las peticiones y quejas que éstos le envían. Tal conclusión puede desprenderse de su legitimación para interponer los recursos de inconstitucionalidad y de amparo, legitimación que es autónoma frente a las Cortes Generales.

Quizá sería posible una solución que, sin ser directa, puesto que las peticiones podrían canalizarse a través de los parlamentarios, obligaría a éstos a trasladarlas al DP al objeto de no interferir las posibles actuaciones de éste en base a la legitimación aludida. En este supuesto, el DP no trataría aquellas quejas o peticiones que hubieran sido objeto de una intervención parlamentaria, salvo en el caso de que encontrara una base para la interposición de los recursos señalados ${ }^{34}$. De todas formas, esta solución puede resultar artificiosa si se admite que el DP puede actuar de oficio ya que, en este supuesto, cualquier tipo de mediatización entre el ciudadano y el DP podría convertirse en un requisito inútil ${ }^{35}$.

De todo lo dicho, y sin perjuicio de la solución anterior que sería posible, parece que la construcción constitucional del DP lleva directamente a esta institución a mantener un contacto inmediato con los ciudadanos. Asimismo, en relación con la admisibilidad de las peticiones o quejas ciudadanas, si se admite que el DP puede actuar de oficio, no tiene ningún sentido la exigencia del requisito de un interés por parte del denunciante, al contrario de lo que sucede en el contencioso-administrativo.

La posibilidad de actuación de oficio abre amplias perspectivas de actuación. Según se desprende de la experiencia escandinava, el Ombudsman, además de las visitas de inspección que lleva a cabo con arreglo a un plan previsto por él mismo, inicia sus actividades o bien a partir de las peticiones que le dirigen los ciudadanos o simplemente a raíz de denuncias aparecidas en los medios de comunicación. A su vez, estos medios le sirven de vehículo para dirigirse a la opinión pública. En este último supuesto, que como los anteriores podría tener vigencia en España, el DP encontraría una limitación derivada de su subordinación a las Cortes, ya que, según parece desprenderse del artículo 54, cualquier informe debería ser presentado previamente a las cámaras.

Ya hemos señalado el papel fundamental que juega la opinión pública

34 O. Alzaga, op. cit., pág. 355, señala que en la hipótesis de que se adoptara la solución del acceso indirecto, habría que dejar «siempre la puerta abierta para que las quejas ciudadanas que no sean tramitadas por los parlamentarios, sigan sin demora su curso al Defensor del Pueblos. Como puede verse, la posible solución a que acabamos de hacer referencia, recoge la propuesta del profesor Alzaga, si bien queda matizada en función de la legitimación del Derecho penal para acudir ante el Tribunal Constitucional.

${ }_{35}$ Cabría no obstante algún mecanismo jurídico tendente a propiciar el acceso indirecto como, por ejemplo, que el Derecho penal sólo estuviera obligado formalmente a dar una respuesta a aquellas peticiones que le llegaran a través de un parlamentario, sin perjuicio de que el tratamiento a fondo de la queja o petición dependiera del arbitrio del Derecho penal. En este sentido cabe señalar que en Suecia, ante el aumento de las quejas dirigidas al Ombudsman, la ley de 1967 introdujo la posibilidad de que éste pudiera archivar una queja si el asunto carecía de importancia pública o privada; véase Legrand, op. cit., página 142. 
como base de la autoridad de la institución que comentamos, y no es preciso insistir en ello. Unicamente, antes de finalizar este trabajo, podríamos referirnos a un problema que, aunque se aparta del carácter principalmente jurídico de estas líneas, no puede ser silenciado. El trasplante de una institución que nace en un medio determinado a otro distinto tropieza con problemas jurídicos, como hemos podido ver, y también con obstáculos sociológicos y políticos. El Ombudsman sueco descansa sobre una opinión pública homogénea, en el sentido de que en ella no se dan oposiciones irreductibles. A partir de esta base, los criterios del Ombudsman a la hora de adoptar una decisión se apoyan en valores fundamentales asumidos por la generalidad de los ciudadanos. Lo que en términos jurídicos equivale a decir que se trata de aquellos valores que, por ser considerados dignos de una salvaguardia especial, se recogen en la Constitución.

Seguramente el medio sociopolítico en que va a moverse nuestro DP no será tan favorable a sus actuaciones como lo es en los países precedentes. Un índice fiable a este respecto es el que nos indique en todo momento el grado de aceptación social de los valores fundamentales recogidos en la Constitución, valores que en gran parte corresponde defender al DP, entre otras instituciones. De ahí que la defensa de los mismos, es decir, la función del DP, pueda chocar en algunos momentos con determinados sectores de una opinión pública que puede estar más o menos dividida.

Pero precisamente en este punto cabe señalar que al DP, en cuanto que es una vía de acceso más al sistema político, corresponden otras funciones de legitimación política y de integración social que no puede revelarnos el método jurídico. En la medida en que el DP colabore a que la Administración sea más respetuosa con las libertades y derechos ciudadanos, a que sea más funcional, está colaborando al mismo tiempo a la necesaria legitimación cotidiana del Estado.

No es cuestión de echar sobre las espaldas del DP tareas que corresponden a otras instituciones y mecanismos previstos en la Constitución o a organizaciones políticas o de intereses que genera la sociedad. Es más, puede decirse que el mismo DP podrá ser de alguna utilidad y, por ello mismo, funcionará cuando todo lo demás marche. 